\title{
KUALITAS SOAL PENILAIAN AKHIR SEMESTER (PAS) BUATAN GURU MATA PELAJARAN KIMIA KELAS XI IPA SMA DI KABUPATEN BARITO TIMUR PADA SEMESTER GANJIL TAHUN AJARAN 2018/2019
}

\author{
Irfan Syani*, Suandi Sidauruk, Ruli Meiliawati \\ Program Studi Pendidikan Kimia, FKIP, Universitas Palangka Raya, Indonesia \\ Email: irfansyani48@gmail.com; Hp: 085787721964
}

\begin{abstract}
ABSTRAK
Fokus utama dalam penelitian ini adalah untuk mengetahui dan mendeskripsikan tingkat Kualitas Soal Penilaian Akhir Semester (PAS) Buatan Guru Mata Pelajaran Kimia Kelas XI IPA SMA di Kabupaten Barito Timur pada Semester Ganjil Tahun Ajaran 2018/2019. Objek dalam penelitian ini adalah soal buatan guru berbentuk uraian dan jawaban siswa hasil Penilaian Akhir Semester (PAS) mata pelajaran Kimia kelas XI IPA SMA A, kelas XI IPA SMA B, dan Kelas XI IPA SMA C, pada semester ganjil tahun ajaran 2018/2019. Teknik pengumpulan data penelitian ini menggunakan metode dokumentasi, yang dianalisis menggunakan logical review dan empirical review. Hasil penelitian menunjukkan kualitas soal PAS buatan guru kimia ditinjau dari analisis logical review diperoleh tingkat kesesuaian soal dengan Kompetensi Dasar sebesar 68\%. Aspek konstruksi soal sebesar 69,16\% dengan kriteria soal tergolong sedang. Aspek materi soal sebesar 98,33\% dengan kriteria sangat baik. Aspek bahasa soal sebesar 76,67\% dengan kriteria cukup baik. Distribusi jenjang ranah kognitif taksonomi bloom adalah C1 sebesar 24\%, C2 sebesar 60\%, C3 sebesar 60\%, C4 sebesar 4\%. Kualitas soal PAS buatan guru kimia ditinjau dari analisis empirical review diperoleh rata-rata soal yang baik berdasarkan indeks kesukaran dan indeks daya beda sebesar $68 \%$ atau 17 soal dari 25 soal yang dianalisis memenuhi acuan kriteria empirical review. Uji reliabilitas yang diperoleh memiliki korelasi yang tinggi yaitu sebesar 0,85 .
\end{abstract}

Kata kunci: daya beda, kualitas soal, reliabilitas, tingkat kesukaran. 
Irfan Syani (282-299)

\section{Pendahuluan}

Keberhasilan suatu proses pembelajaran tidaklah terlepas dari sebuah proses penilaian hasil belajar yang handal. Pelaksanaan ujian yang baik sangat tergantung pada ketersediaan alat ukur yang berkualitas. Penilaian hasil belajar merupakan bagian dari program pendidikan untuk mengetahui keberhasilan belajar siswa. Penilaian hasil belajar juga dapat memberikan gambaran tentang kualitas pembelajaran dalam rangka perbaikan kualitas pendidikan secara umum.

Hasil wawancara yang dilakukan pada bulan Januari 2019 kepada beberapa guru SMA di Kabupaten Barito Timur, diketahui bahwa guru belum secara maksimal mengembangkan kemampuannya dalam menyusun tes yang baik. Guru menyusun naskah soal mengambil dari buku pelajaran, buku bank soal, internet, dan soal-soal tahun sebelumnya. Setelah soal selesai dibuat, guru langsung menggunakannya untuk tes, padahal naskah soal untuk menguji kemampuan siswa tersebut karakteristik soalnya belum jelas karena belum dilakukan tahap analisis. Tahap analisis butir soal yang diabaikan dapat menyebabkan soal tes tidak mampu mengukur kemampuan siswa yang sesungguhnya.

Tes dapat memberikan gambaran sesungguhnya tentang pencapaian kompetensi yang diharapkan, perangkat tes harus memenuhi persyaratan alat ukur yang baik. Untuk mengetahui mutu seperangkat soal dalam berbagai aspek dan mengidentifikasi kekurangan-kekurangan dalam tes, maka perlu dilakukan analisis butir soal. Gambaran tentang baik tidaknya tes yang digunakan tercermin pada karakteristik perangkat tes itu sendiri, yaitu: validitas, reliabilitas, tingkat kesukaran, daya beda (Arikunto, 2013). 
Menurut Purwanto (2008) untuk melaksanakan evaluasi hasil belajar dan mengajar, seorang guru dapat menggunakan dua macam tes, yakni tes yang telah distandarkan (standardized test) dan tes buatan guru sendiri (teacher-made test). Standardized test ialah tes yang telah mengalami proses standardisasi, yakni proses validasi dan keandalan (reliability) sehingga tes tersebut benar-benar valid dan andal untuk suatu tujuan dan bagi suatu kelompok tertentu. Putra (2013) menyatakan bahwa tes buatan guru adalah tes yang dibuat oleh para guru kelas itu sendiri. Tes tersebut dimaksud untuk mengukur tingkat keberhasilan peserta didik mencapai komptensi setelah berlangsungnya proses pembelajaran yang dikelola oleh guru kelas.

Arikunto (2013) menyatakan bahwa tes subjektif pada umumnya berbentuk uraian (esai), yaitu sejenis tes kemajuan belajar yang memerlukan jawaban bersifat pembahasan. Soal bentuk esai berkisar 5-10 soal yang dikerjakan dalam waktu 90-120 menit. Widoyoko (2016) menyatakan bahwa tes subjektif merupakan butir soal yang mengandung pertanyaan atau tugas yang jawaban atau pengerjaan soal tersebut harus dilakukan dengan cara mengekspresikan pikiran peserta tes. Tes subjektif ini sistem penskorannya dipengaruhi oleh jawaban peserta tes dan pemberi skor. Jawaban yang sama dapat memiliki skor yang berbeda oleh pemberi skor yang berlainan. Tes subjektif pada umumnya berbentuk uraian (esai).

Widoyoko (2016) menyatakan bahwa untuk menghasilkan butir-butir tes uraian yang baik, bagi penyusun tes diharapkan memperhatikan hal-hal berikut:

a) Butir-butir tes hendaknya meliputi ide-ide pokok dari materi yang diujikan, dan kalau mungkin disusun soal yang sifatnya komprehensif yang mampu 
mewakili materi pokok dalam mata pelajaran yang diujikan.

b) Sebaiknya butir tes tidak mengambil kalimat-kalimat yang disalin langsung dari buku atau catatan. Penyusunan butir tes yang menyalin langsug dari buku atau catatan mendorong siswa hanya menghafalkan materi ujian.

c) Pada waktu menyusun butir tes sudah dilengkapi kunci jawaban serta pedoman penskoran.

d) Hendaknya diusahakan pertanyaannya bervariasi antara "jelaskan", “mengapa”, “bagaimana”, “uraikan”, dan “bandingkan”agar dapat diketahui lebih jauh tingkat penguasaan siswa terhadap bahan tes.

e) Hendaknya rumusan butir tes disusun sedemikian rupa sehingga mudah dipahami oleh peserta tes. Hindari penggunaan istilah atau kata-kata yang memiliki makna ganda.

Berkaitan dengan permasalahan di atas, agar kualitas soal Penilaian Akhir Semester (PAS) Buatan Guru Mata Pelajaran Kimia Kelas XI IPA SMA di Kabupaten Barito Timur Pada Semester Ganjil Tahun Ajaran 2018/2019 meningkat, maka peneliti ingin menyelesaikan masalah dengan melakukan analisis terhadap soal buatan guru. Tahapan analisis meliputi analisis logical review yang mencakup kesesuaian soal dengan Kompetensi Dasar, Aspek konstruksi, materi dan bahasa, dan jenjang ranah kognitif taksonomi Bloom, dan empirical review mencakup analisis daya beda, tingkat kesukaran dan reliabilitas soal.

Pemilihan analisis menggunakan logical review empirical review bertujuan untuk mengetahui dan mendeskripsikan Kualitas Soal Penilaian Akhir Semester (PAS) buatan guru mata pelajaran kimia kelas XI IPA di beberapa SMA 
Kabupaten Barito Timur pada semester ganjil tahun ajaran 2018/2019, soal yang sudah dianalisis kemudian dikriteriakan dengan acuan kriteria untuk menentukan baik buruknya soal, jika soal baik maka akan disimpan di bank soal dan jika tidak baik akan dibuang atau direvisi.

\section{Metodologi Penelitian}

Penelitian ini dilaksanakan di tiga sekolah SMA Kabupaten Barito Timur, yaitu SMA A, SMA B dan SMA C. Waktu pelaksanaan Penilaian Akhir Semester (PAS) pada bulan Desember 2018 dan waktu peneliti mengumpulkan data pada bulan Januari - Februari 2019. Objek dalam penelitian ini adalah soal PAS buatan guru mata pelajaran kimia kelas XI IPA SMA A, SMA B, SMA C di Kab. Barito Timur. SMA A membuat lima soal uraian dengan jumlah lembar jawaban siswa sebanyak 133 lembar, SMA B membuat 10 soal uraian dengan jumlah lembar jawaban siswa sebanyak 104 lembar, dan SMA C membuat 10 soal uraian dengan jumlah lembar jawaban siswa sebanyak 49 lembar.

Data diperoleh melalui perantara guru kimia dengan meminta ijin untuk menyimpankan setelah pelaksanaan PAS selesai kemudian peneliti meminta ijin kepada masing-masing kepala sekolah SMA di Kab. Barito Timur untuk mengadakan penelitian. Data yang diperoleh berupa paket soal yang terdiri soal, lembar jawaban berserta kunci jawaban dan rubric penskoran. Data ini dianalisis secara logical review dan empirical review. Logical review bertujuan untuk mengetahui validitas isi soal yang mencakup kesesuaian soal dengan Kompetensi Dasar, aspek konstruksi, materi dan bahasa, dan jenjang ranah kognitif taksonomi 
Bloom. Empirical review bertujuan untuk mengetahui indeks tingkat kesukaran, daya beda soal dan reliabilitas soal.

\section{Hasil Dan Pembahasan}

Hasil analisis terhadap kualitas soal dilakukan melalui dua cara, yaitu: (1) logical review dan (2) empirical review. Logical review dilakukan untuk mengetahui dan mendiskripsikan validitas isi soal ditinjau dari kesesuaian soal dengan Kompetensi Dasar, aspek konstruksi, materi dan bahasa, pengelompokan soal berdasarkan tingkatan kognitif menurut taksonomi Bloom. Empirical review dilakukan untuk mendapatkan indeks tingkat kesukaran, indeks daya beda dan indeks reliabilitas soal. Hasil penelitian diperoleh data sebagai berikut:

\section{Logical review}

\section{Analisis Kesesuaian Soal dengan Kompetensi Dasar}

Hasil analisis soal dari kesesuaian soal dengan Kompetensi Dasar didapatkan dengan menggunakan rater untuk menilai, hasil analisis soal dapat dilihat pada Gambar berikut:

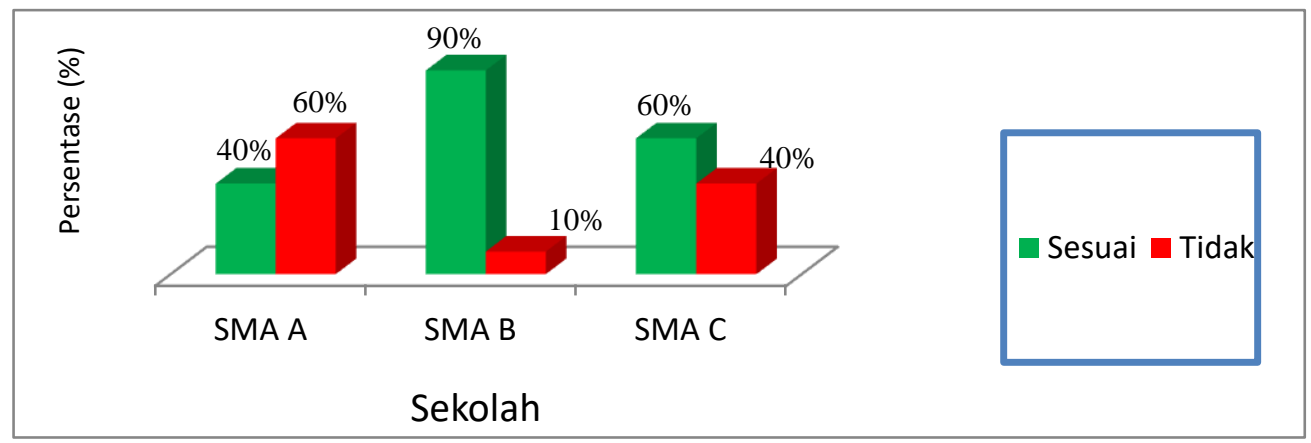

Gambar 1. kesesuaian soal dengan Kompetensi Dasar

Ditinjau dari kesesuaian soal dengan Kompetensi Dasar maka soal yang tidak sesuai lebih sedikit dibandingkan soal yang sesuai. Soal yang sesuai dengan 
Kompetensi Dasar di SMA A sebesar 40\%, Soal yang sesuai dengan Kompetensi

Dasar di SMA B sebesar 90\%, Soal yang sesuai dengan Kompetensi Dasar di SMA C sebesar $60 \%$. Jumlah keseluruhan soal yang sesuai dengan Kompetensi Dasar berdasarkan ketiga sekolah tersebut sebanyak tujuh belas soal dan delapan soal yang tidak sesuai dengan Kompetensi Dasar.

\section{Analisis Soal dari Aspek Konstruksi, Materi, dan Bahasa}

Hasil analisis soal dari aspek konstruksi, materi, dan bahasa didapatkan dengan menggunakan penilai untuk menilai, hasil analisis soal berdasarkan aspek konstruksi, materi dan bahasa pada soal kimia kelas XI buatan guru dari SMA A adalah sebagai berikut:

Tabel 1. Aspek konstruksi, materi dan bahasa di SMA A

\begin{tabular}{|c|c|c|c|c|c|}
\hline \multirow[b]{2}{*}{ Aspek yang Ditelaah } & \multirow[b]{2}{*}{ Kriteria } & \multirow[b]{2}{*}{$\begin{array}{c}\text { No } \\
\text { Soal } \\
\text { Sesuai }\end{array}$} & \multirow{2}{*}{$\begin{array}{c}\text { Jumlah dan } \\
\text { Tingkat } \\
\text { Kesesuaian Soal } \\
(\%)\end{array}$} & \multicolumn{2}{|c|}{ Kategori Soal } \\
\hline & & & & $\begin{array}{c}\text { Per } \\
\text { Aspek }\end{array}$ & $\begin{array}{c}\text { Rata- } \\
\text { Rata } \\
(\%)\end{array}$ \\
\hline \multicolumn{6}{|l|}{ Aspek Konstruksi } \\
\hline $\begin{array}{l}\text { Ada petunjuk yang jelas } \\
\text { tentang cara mengerjakan soal }\end{array}$ & Sesuai & $\begin{array}{l}1,2,3 \\
4,5\end{array}$ & $\begin{array}{c}5 \\
(100 \%)\end{array}$ & $\begin{array}{l}\text { Sangat } \\
\text { Baik }\end{array}$ & \multirow{4}{*}{$\begin{array}{l}85 \% \\
\text { (Baik) }\end{array}$} \\
\hline $\begin{array}{l}\text { Menggunakan kata tanya atau } \\
\text { perintah yang menuntut } \\
\text { jawaban uraian }\end{array}$ & Sesuai & 1,3 & $\begin{array}{c}2 \\
(40 \%)\end{array}$ & $\begin{array}{l}\text { Kurang } \\
\text { baik }\end{array}$ & \\
\hline $\begin{array}{l}\text { Tabel, gambar, grafik, peta, } \\
\text { atau yang sejenisnya disajikan } \\
\text { dengan jelas dan terbaca }\end{array}$ & Sesuai & $\begin{array}{l}1,2,3 \\
\quad 4,5\end{array}$ & $\begin{array}{c}5 \\
(100 \%)\end{array}$ & $\begin{array}{l}\text { Sangat } \\
\text { Baik }\end{array}$ & \\
\hline Ada pedoman penskoran & Sesuai & $\begin{array}{l}1,2,3 \\
\quad 4,5\end{array}$ & $\begin{array}{c}5 \\
(100 \%)\end{array}$ & $\begin{array}{l}\text { Sangat } \\
\text { Baik }\end{array}$ & \\
\hline \multicolumn{6}{|l|}{ Aspek Materi } \\
\hline $\begin{array}{l}\text { Batasan pertanyaan dan } \\
\text { jawaban yang diharapkan } \\
\text { sesuai }\end{array}$ & Sesuai & $\begin{array}{c}1,2,3 \\
4,5\end{array}$ & $\begin{array}{c}5 \\
(100 \%)\end{array}$ & $\begin{array}{l}\text { Sangat } \\
\text { Baik }\end{array}$ & \multirow{2}{*}{$\begin{array}{c}100 \% \\
\text { (Sangat } \\
\text { Baik) }\end{array}$} \\
\hline $\begin{array}{l}\text { Isi materi yang ditanyakan } \\
\text { sesuai dengan jenjang, jenis } \\
\text { satuan pendidikan, dan tingkat } \\
\text { kelas }\end{array}$ & Sesuai & $\begin{array}{l}1,2,3 \\
4,5\end{array}$ & $\begin{array}{c}5 \\
(100 \%)\end{array}$ & $\begin{array}{l}\text { Sangat } \\
\text { Baik }\end{array}$ & \\
\hline
\end{tabular}




\begin{tabular}{|c|c|c|c|c|c|}
\hline \multirow[b]{2}{*}{ Aspek yang Ditelaah } & \multirow[b]{2}{*}{ Kriteria } & \multirow[b]{2}{*}{$\begin{array}{c}\text { No } \\
\text { Soal } \\
\text { Sesuai }\end{array}$} & \multirow{2}{*}{$\begin{array}{c}\text { Jumlah dan } \\
\text { Tingkat } \\
\text { Kesesuaian Soal } \\
(\%)\end{array}$} & \multicolumn{2}{|c|}{ Kategori Soal } \\
\hline & & & & $\begin{array}{c}\text { Per } \\
\text { Aspek }\end{array}$ & $\begin{array}{c}\text { Rata- } \\
\text { Rata } \\
(\%)\end{array}$ \\
\hline \multicolumn{6}{|l|}{ Aspek Bahasa } \\
\hline $\begin{array}{l}\text { Rumusan kalimat soal } \\
\text { komunikatif }\end{array}$ & Sesuai & $\begin{array}{c}1,2,3 \\
5\end{array}$ & $\begin{array}{c}4 \\
(80 \%)\end{array}$ & Baik & \multirow{2}{*}{$\begin{array}{c}90 \% \\
\text { (Sangat } \\
\text { Baik) }\end{array}$} \\
\hline $\begin{array}{l}\text { Butir soal menggunakan } \\
\text { bahasa Indonesia yang baku. }\end{array}$ & Sesuai & $\begin{array}{c}1,2,3 \\
4,5\end{array}$ & $\begin{array}{c}5 \\
(100 \%)\end{array}$ & $\begin{array}{l}\text { Sangat } \\
\text { Baik }\end{array}$ & \\
\hline
\end{tabular}

Tabel 1 meringkas analisis logical review berdasarkan aspek konstruksi, materi dan bahasa dalam bentuk soal uraian diperoleh bahwa pada SMA A aspek konstruksi pada poin ada petunjuk yang jelas tentang cara mengerjakan soal memiliki kriteria sangat baik (100\%), pada poin menggunakan kata tanya atau perintah yang menuntut jawaban uraian memiliki kriteria kurang baik (40\%), pada poin tabel, gambar, grafik, peta, atau yang sejenisnya disajikan dengan jelas dan terbaca memiliki kriteria sangat baik (100\%) dan pada poin ada pedoman penskoran memiliki kriteria sangat baik (100\%). Secara keseluruhan untuk penilaian aspek konstruksi SMA A memiliki kategori soal yang baik dengan persentase $85 \%$.

Aspek materi pada poin batasan pertanyaan dan jawaban yang diharapkan sesuai memiliki kriteria sangat baik (100\%), pada poin isi materi yang ditanyakan sesuai dengan jenjang, jenis satuan pendidikan, dan tingkat kelas memiliki kriteria sangat baik (100\%). Secara keseluruhan untuk penilaian aspek materi SMA A memiliki kategori soal yang sangat baik dengan persentase $100 \%$.

Aspek bahasa pada poin rumusan kalimat soal komunikatif memiliki kriteria baik (80\%), pada poin butir soal menggunakan bahasa Indonesia yang baku memiliki kriteria sangat baik (100\%). Secara keseluruhan untuk penilaian aspek bahasa SMA A memiliki kategori soal yang sangat baik dengan persentase $90 \%$. 
Hasil analisis soal dari aspek materi, konstruksi dan bahasa pada soal kimia kelas XI buatan guru dari SMA B adalah sebagai berikut:

Tabel 2. Aspek konstruksi, materi dan bahasa di SMA B

\begin{tabular}{|c|c|c|c|c|c|}
\hline \multirow[b]{2}{*}{ Aspek yang Ditelaah } & \multirow[b]{2}{*}{ Kriteria } & \multirow[b]{2}{*}{$\begin{array}{l}\text { No Soal } \\
\text { sesuai }\end{array}$} & \multirow{2}{*}{$\begin{array}{c}\text { Jumlah } \\
\text { dan } \\
\text { Tingkat Ke } \\
\text { sesuain } \\
\text { Soal }(\%) \\
\end{array}$} & \multicolumn{2}{|c|}{ Kategori Soal } \\
\hline & & & & $\begin{array}{c}\text { Per } \\
\text { Aspek }\end{array}$ & $\begin{array}{c}\text { Rata- } \\
\text { Rata }(\%)\end{array}$ \\
\hline \multicolumn{6}{|l|}{ Aspek Konstruksi } \\
\hline $\begin{array}{l}\text { Ada petunjuk yang jelas tentang } \\
\text { cara mengerjakan soal }\end{array}$ & Sesuai & - & $\begin{array}{c}0 \\
(0 \%)\end{array}$ & $\begin{array}{c}\text { Kurang } \\
\text { Baik }\end{array}$ & \multirow{4}{*}{$\begin{array}{c}55 \% \\
\text { (Kurang } \\
\text { Baik) }\end{array}$} \\
\hline $\begin{array}{l}\text { Menggunakan kata tanya atau } \\
\text { perintah yang menuntut jawaban } \\
\text { uraian }\end{array}$ & Sesuai & $3,5,6,7$ & $\begin{array}{c}4 \\
(40 \%)\end{array}$ & $\begin{array}{c}\text { Kurang } \\
\text { baik }\end{array}$ & \\
\hline $\begin{array}{l}\text { Tabel, gambar, grafik, peta, atau } \\
\text { yang sejenisnya disajikan } \\
\text { dengan jelas dan terbaca }\end{array}$ & Sesuai & $\begin{array}{l}1,2,3,4 \\
5,6,7,8\end{array}$ & $\begin{array}{c}8 \\
(80 \%)\end{array}$ & Baik & \\
\hline Ada pedoman penskoran. & Sesuai & $\begin{array}{l}1,2,3,4 \\
5,6,7,8 \\
\quad 9,10\end{array}$ & $\begin{array}{c}10 \\
(100 \%)\end{array}$ & $\begin{array}{l}\text { Sangat } \\
\text { Baik }\end{array}$ & \\
\hline \multicolumn{6}{|l|}{ Aspek Materi } \\
\hline $\begin{array}{l}\text { Batasan pertanyaan dan jawaban } \\
\text { yang diharapkan sesuai }\end{array}$ & Sesuai & $\begin{array}{c}1,2,4,5 \\
6,7,8,9 \\
10\end{array}$ & $\begin{array}{c}9 \\
(90 \%)\end{array}$ & $\begin{array}{l}\text { Sangat } \\
\text { Baik }\end{array}$ & \multirow{2}{*}{$\begin{array}{c}95 \% \\
\text { (Sangat } \\
\text { Baik) }\end{array}$} \\
\hline $\begin{array}{l}\text { Isi materi yang ditanyakan sesuai } \\
\text { dengan jenjang, jenis satuan } \\
\text { pendidikan, dan tingkat kelas }\end{array}$ & Sesuai & $\begin{array}{l}1,2,3,4 \\
5,6,7,8 \\
\quad 9,10\end{array}$ & $\begin{array}{c}10 \\
(100 \%)\end{array}$ & $\begin{array}{l}\text { Sangat } \\
\text { Baik }\end{array}$ & \\
\hline \multicolumn{6}{|l|}{ Aspek Bahasa } \\
\hline $\begin{array}{l}\text { Rumusan kalimat soal } \\
\text { komunikatif }\end{array}$ & Sesuai & $\begin{array}{l}1,2,3,4 \\
5,6,7,8 \\
9\end{array}$ & $\begin{array}{c}9 \\
(90 \%)\end{array}$ & $\begin{array}{l}\text { Sangat } \\
\text { Baik }\end{array}$ & \multirow{2}{*}{$\begin{array}{l}\text { 70\% } \\
\text { (Cukup } \\
\text { Baik) }\end{array}$} \\
\hline $\begin{array}{l}\text { Butir soal menggunakan bahasa } \\
\text { Indonesia yang baku. }\end{array}$ & Sesuai & $\begin{array}{c}1,2,3,4, \\
5\end{array}$ & $\begin{array}{c}5 \\
(50 \%)\end{array}$ & $\begin{array}{c}\text { Kurang } \\
\text { Baik }\end{array}$ & \\
\hline
\end{tabular}

Tabel 2 meringkas analisis logical review berdasarkan aspek konstruksi, materi dan bahasa dalam bentuk soal uraian diperoleh bahwa pada SMA B aspek konstruksi pada poin ada petunjuk yang jelas tentang cara mengerjakan soal memiliki kriteria kurang baik $(0 \%)$, pada poin menggunakan kata tanya atau perintah yang menuntut jawaban uraian memiliki kriteria kurang baik (40\%), pada poin tabel, gambar, grafik, peta, atau yang sejenisnya disajikan dengan jelas 
dan terbaca memiliki kriteria baik $(80 \%)$ dan pada poin ada pedoman penskoran memiliki kriteria sangat baik (100\%). Secara keseluruhan untuk penilaian aspek konstruksi SMA B memiliki kategori soal yang kurang baik dengan persentase $55 \%$.

Aspek materi pada poin batasan pertanyaan dan jawaban yang diharapkan sesuai memiliki kriteria sangat baik $(90 \%)$, pada poin isi materi yang ditanyakan sesuai dengan jenjang, jenis satuan pendidikan, dan tingkat kelas memiliki kriteria sangat baik (100\%). Secara keseluruhan untuk penilaian aspek materi SMA B memiliki kategori soal yang sangat baik dengan persentase $95 \%$.

Aspek bahasa pada poin rumusan kalimat soal komunikatif memiliki kriteria sangat baik (90\%), pada poin butir soal menggunakan bahasa Indonesia yang baku memiliki kriteria kurang baik (50\%). Secara keseluruhan untuk penilaian aspek bahasa SMA B memiliki kategori soal yang cukup baik dengan persentase $70 \%$.

Hasil analisis soal dari aspek materi, konstruksi dan bahasa pada soal kimia kelas XI buatan guru dari SMA C adalah sebagai berikut:

Tabel 3. Aspek konstruksi, materi dan bahasa di SMA C

\begin{tabular}{|c|c|c|c|c|c|}
\hline \multirow[b]{2}{*}{ Aspek yang Ditelaah } & \multirow[b]{2}{*}{ Kriteria } & \multirow[b]{2}{*}{$\begin{array}{c}\text { No soal } \\
\text { sesuai }\end{array}$} & \multirow{2}{*}{$\begin{array}{c}\text { Jumlah dan } \\
\text { Tingkat } \\
\text { Kesesuaian Soal } \\
(\%)\end{array}$} & \multicolumn{2}{|c|}{ Kategori Soal } \\
\hline & & & & $\begin{array}{c}\text { Per } \\
\text { Aspek }\end{array}$ & $\begin{array}{c}\text { Rata- } \\
\text { Rata }(\%)\end{array}$ \\
\hline \multicolumn{6}{|l|}{ Aspek Konstruksi } \\
\hline $\begin{array}{l}\text { Ada petunjuk yang jelas } \\
\text { tentang cara mengerjakan } \\
\text { soal }\end{array}$ & Sesuai & - & $\begin{array}{c}0 \\
(0 \%)\end{array}$ & $\begin{array}{c}\text { Kurang } \\
\text { Baik }\end{array}$ & \multirow{4}{*}{$\begin{array}{c}67.5 \% \\
\text { (Sedang) }\end{array}$} \\
\hline $\begin{array}{l}\text { Menggunakan kata tanya } \\
\text { atau perintah yang menuntut } \\
\text { jawaban uraian }\end{array}$ & Sesuai & $\begin{array}{c}1,3,4,5 \\
6,7,8 \\
10\end{array}$ & $\begin{array}{c}8 \\
(80 \%)\end{array}$ & Baik & \\
\hline $\begin{array}{l}\text { Tabel, gambar, grafik, peta, } \\
\text { atau yang sejenisnya } \\
\text { disajikan dengan jelas dan } \\
\text { terbaca }\end{array}$ & Sesuai & $\begin{array}{l}1,3,4,5 \\
6,7,8,9 \\
10\end{array}$ & $\begin{array}{c}9 \\
(90 \%)\end{array}$ & $\begin{array}{l}\text { Sangat } \\
\text { Baik }\end{array}$ & \\
\hline Ada pedoman penskoran. & Sesuai & $\begin{array}{l}1,2,3,4, \\
5,6,7,8,\end{array}$ & $\begin{array}{c}10 \\
(100 \%)\end{array}$ & $\begin{array}{c}\text { Sangat } \\
\text { Baik }\end{array}$ & \\
\hline
\end{tabular}




\begin{tabular}{|c|c|c|c|c|c|}
\hline \multirow[b]{2}{*}{ Aspek yang Ditelaah } & \multirow[b]{2}{*}{ Kriteria } & \multirow[b]{2}{*}{$\begin{array}{l}\text { No soal } \\
\text { sesuai }\end{array}$} & \multirow{2}{*}{$\begin{array}{c}\text { Jumlah dan } \\
\text { Tingkat } \\
\text { Kesesuaian Soal } \\
(\%)\end{array}$} & \multicolumn{2}{|c|}{ Kategori Soal } \\
\hline & & & & $\begin{array}{c}\text { Per } \\
\text { Aspek }\end{array}$ & $\begin{array}{c}\text { Rata- } \\
\text { Rata }(\%)\end{array}$ \\
\hline & & 9,10 & & & \\
\hline \multicolumn{6}{|l|}{ Aspek Materi } \\
\hline $\begin{array}{l}\text { Batasan pertanyaan dan } \\
\text { jawaban yang diharapkan } \\
\text { sesuai }\end{array}$ & Sesuai & $\begin{array}{l}1,2,3,4 \\
5,6,7,8 \\
\quad 9,10\end{array}$ & $\begin{array}{c}10 \\
(100 \%)\end{array}$ & $\begin{array}{l}\text { Sangat } \\
\text { Baik }\end{array}$ & \multirow{2}{*}{$\begin{array}{c}100 \% \\
\text { (Sangat } \\
\text { Baik) }\end{array}$} \\
\hline $\begin{array}{l}\text { Isi materi yang ditanyakan } \\
\text { sesuai dengan jenjang, jenis } \\
\text { satuan pendidikan, dan } \\
\text { tingkat kelas }\end{array}$ & Sesuai & $\begin{array}{l}1,2,3,4 \\
5,6,7,8 \\
\quad 9,10\end{array}$ & $\begin{array}{c}10 \\
(100 \%)\end{array}$ & $\begin{array}{l}\text { Sangat } \\
\text { Baik }\end{array}$ & \\
\hline \multicolumn{6}{|l|}{ Aspek Bahasa } \\
\hline $\begin{array}{l}\text { Rumusan kalimat soal } \\
\text { komunikatif }\end{array}$ & Sesuai & $\begin{array}{c}1,3,4,5 \\
6,7,8,9 \\
10\end{array}$ & $\begin{array}{c}9 \\
(90 \%)\end{array}$ & $\begin{array}{l}\text { Sangat } \\
\text { Baik }\end{array}$ & \multirow{2}{*}{$\begin{array}{c}70 \% \\
\text { (Cukup } \\
\text { Baik) }\end{array}$} \\
\hline $\begin{array}{l}\text { Butir soal menggunakan } \\
\text { bahasa Indonesia yang baku. }\end{array}$ & Sesuai & $\begin{array}{c}1,2,3,4 \\
5\end{array}$ & $\begin{array}{c}5 \\
(50 \%)\end{array}$ & $\begin{array}{l}\text { Kurang } \\
\text { Baik }\end{array}$ & \\
\hline
\end{tabular}

Tabel 3 meringkas analisis logical review berdasarkan aspek konstruksi, materi, dan bahasa dalam bentuk soal uraian diperoleh bahwa pada SMA C aspek konstruksi pada poin ada petunjuk yang jelas tentang cara mengerjakan soal memiliki kriteria kurang baik $(0 \%)$, pada poin menggunakan kata tanya atau perintah yang menuntut jawaban uraian memiliki kriteria baik $(80 \%)$, pada poin tabel, gambar, grafik, peta, atau yang sejenisnya disajikan dengan jelas dan terbaca memiliki kriteria sangat baik (90\%) dan pada poin ada pedoman penskoran memiliki kriteria sangat baik (100\%). Secara keseluruhan untuk penilaian aspek konstruksi SMA C memiliki kategori soal yang sedang dengan persentase $67,5 \%$.

Aspek materi pada poin batasan pertanyaan dan jawaban yang diharapkan sesuai memiliki kriteria sangat baik $(100 \%)$, pada poin isi materi yang ditanyakan sesuai dengan jenjang, jenis satuan pendidikan, dan tingkat kelas memiliki kriteria sangat baik (100\%). Secara keseluruhan untuk penilaian aspek materi SMA C 
memiliki kategori soal yang sangat baik dengan persentase $100 \%$.

Aspek bahasa pada poin rumusan kalimat soal komunikatif memiliki kriteria sangat baik (90\%), pada poin butir soal menggunakan bahasa Indonesia yang baku memiliki kriteria kurang baik (50\%). Secara keseluruhan untuk penilaian aspek bahasa SMA C memiliki kategori soal yang cukup baik dengan persentase $70 \%$.

\section{Pengelompokkan Soal Berdasarkan Tingkat Kognitif Menurut Taksonomi Bloom}

Penilaian terhadap aspek penguasaan materi (kognitif) dilakukan analisis soal tes yang digunakan untuk mengukur ranah kognitif peserta didik. Berikut pengelompokkan soal berdasarkan tingkatan kognitif menurut taksonomi Bloom:

Tabel 4. Taksonomi Bloom

\begin{tabular}{|c|c|c|c|c|}
\hline Taksonomi Bloom & SMA A & SMA B & SMA C & $\sum_{(\%)}$ \\
\hline $\mathrm{C} 1$ & 2 & - & 4 & $\begin{array}{c}6 \\
(24 \%) \\
\end{array}$ \\
\hline $\mathrm{C} 2$ & 1 & - & 2 & $\begin{array}{c}3 \\
(12 \%)\end{array}$ \\
\hline C3 & 2 & 9 & 4 & $\begin{array}{c}15 \\
(60 \%)\end{array}$ \\
\hline $\mathrm{C} 4$ & - & 1 & - & $\begin{array}{c}1 \\
(4 \%)\end{array}$ \\
\hline $\mathrm{C} 5$ & - & - & - & \\
\hline C6 & - & - & - & \\
\hline$\Sigma$ & & & & $\begin{array}{c}25 \\
(100 \%)\end{array}$ \\
\hline
\end{tabular}

Tabel 4 menunjukkan bahwa hasil tingkat kesesuaian soal dengan taksonomi Bloom soal PAS kimia Kelas XI IPA bentuk soal uraian bahwa pada SMA A ada dua soal merupakan soal yang termasuk $\mathrm{C} 1$, satu soal merupakan soal yang termasuk C2, dua soal merupakan soal yang termasuk C3. SMA B ada sembilan soal merupakan soal yang termasuk C3, dan satu soal merupakan soal yang 
termasuk C4. SMA C ada empat soal merupakan soal yang termasuk C1, dua soal merupakan soal yang termasuk C2, empat soal merupakan soal yang termasuk C3.

Uraian di atas menjelaskan bahwa pada tingkat mengingat $(\mathrm{C} 1)$ didominasi oleh SMA C, pada tingkat memahami (C2) didominasi oleh SMA C, pada tingkat menerapkan (C3) didominasi oleh SMA B, pada tingkat menganalisis (C4) didominasi oleh SMA B, sedangkan pada tingkat mengevaluasi (C5) dan mencipta (C6) dari ketiga sekolah tidak ada soal yang termasuk kategori tersebut.

\section{Empirical review}

\section{Analisis Tingkat kesukaran}

Hasil analisis data indeks kesukaran soal Penilaian Akhir Semester (PAS) kimia kelas XI IPA beberapa SMA di Kabupaten Barito Timur pada semester ganjil tahun ajaran 2018/2019 dapat dilihat pada Gambar berikut:

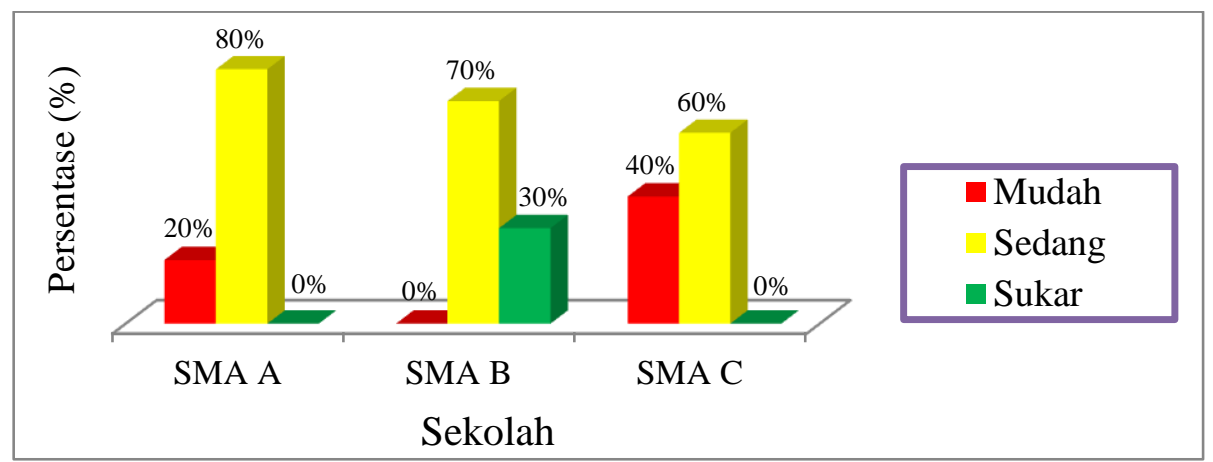

Gambar 2. Tingkat Kesukaran Soal Penilaian Akhir Semester (PAS) Kimia Kelas XI IPA SMA di Kabupaten Barito Timur

Gambar di atas menunjukkan bahwa soal yang dikategorikan mudah didominasi oleh SMA C, soal yang baik yang dikategorikan sedang banyak didominasi oleh SMA A dan soal yang dikategorikan sukar banyak terdapat pada soal yang dibuat oleh SMA B. SMA A membuat soal yang baik (kategori sedang) sebesar 80\%, SMA B membuat soal yang baik (kategori sedang) sebesar $70 \%$, sedangkan SMA C membuat soal yang baik (kategori sedang) sebesar $60 \%$.

Butir soal yang dinyatakan tidak baik hendaknya ditindaklanjuti oleh 
pembuat soal. Butir soal yang masuk dalam kategori sulit diteliti ulang sehingga dapat diketahui faktor yang menyebabkan butir soal yang bersangkutan sulit dijawab oleh siswa. Demikian juga dengan butir soal yang berada pada kategori mudah. Setelah dilakukan perbaikan, butir-butir soal tersebut dapat dikeluarkan kembali pada tes berikutnya atau disimpan di bank soal. Butir soal yang sukar dijawab oleh peserta tes dapat disebabkan oleh beberapa hal. Pengecekan terhadap kunci jawaban perlu dilakukan. Apabila kunci jawaban sudah benar, sulitnya soal dimungkinkan karena materi yang ditanyakan belum diajarkan atau belum tuntas pembelajarannya, sehingga kompetensi minimum yang harus dikuasai siswa belum tercapai. Faktor lain yang berpengaruh adalah materi yang diukur tidak cocok ditanyakan dengan menggunakan bentuk soal yang diberikan dan pernyataan atau kalimat soal terlalu panjang.

\section{Analisis Daya beda}

Hasil analisis data indeks daya beda soal Penilaian Akhir Semester (PAS) kimia kelas XI IPA beberapa SMA di Kabupaten Barito Timur pada semester ganjil tahun ajaran 2018/2019 dapat dilihat pada Gambar berikut:

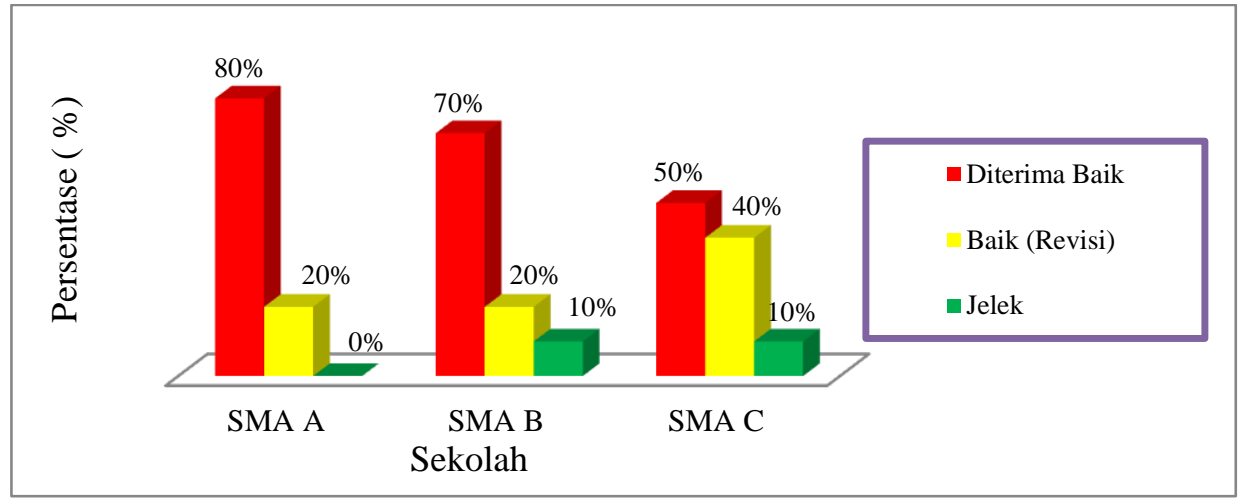

Gambar 3. Daya Beda Soal Penilaian Akhir Semester (PAS) Kimia Kelas XI IPA SMA di Kabupaten Barito Timur

Gambar di atas menunjukkan bahwa soal yang dapat membedakan siswa (i) yang termasuk berkemampuan tinggi dengan siswa (i) berkemampuan rendah 
(soal diterima baik) terdapat pada ketiga sekolah (SMA A, SMA B, SMA C), artinya soal yang diterima baik lebih banyak mendominasi dari pada soal yang direvisi ataupun yang dibuang.

Soal buatan guru SMA A terdapat $80 \%$ soal yang baik dan $20 \%$ soal yang jelek, soal buatan guru SMA B terdapat $70 \%$ soal yang baik dan $30 \%$ soal yang jelek dan soal buatan guru SMA C terdapat $60 \%$ soal yang baik dan $40 \%$ soal yang jelek.

\section{Analisis Reliabilitas}

Reliabilitas soal penelitian ini dapat dilihat dari nilai koefisien Alpha yang diperoleh. Hasil analisis reliabilitas soal PAS dari tiga sekolah yang diteliti disajikan dalam Tabel berikut:

Tabel Hasil Analisis Reliabilitas Soal

\begin{tabular}{ccc}
\hline Sekolah & R & Keterangan \\
\hline SMA A & 0,872 & Tinggi \\
\hline SMA B & 0,898 & Tinggi \\
\hline SMA C & 0,796 & Tinggi \\
\hline
\end{tabular}

Analisis reliabilitas yang diperoleh yaitu koefisien reliabilitas untuk SMA A,

SMA B, dan SMA C masing-masing memiliki koefisien reliabilitas pada angka 0,872, 0,898, dan 0,796). Hasil analisis menunjukkan bahwa reliabilitas soal masing-masing sekolah memiliki korelasi yang tinggi. Pengukuran yang memiliki reliabilitas tinggi, yaitu pengukuran yang mampu memberikan hasil ukur yang terpercaya (reliable). Instrumen tes berupa soal PAS bentuk uraian dari tiap sekolah mempunyai ketepatan dan keajegan yang tinggi. Tes yang memiliki konsistensi reliabilitas tinggi adalah akurat dan tergeneralisasi terhadap kesempatan testing lainnya. 
Irfan Syani (282-299)

\section{Kesimpulan}

Kualitas soal Penilaian Akhir Semester (PAS) buatan guru mata pelajaran kimia kelas XI IPA SMA di Kabupaten Barito Timur pada semester ganjil tahun ajaran 2018/2019 secara logical review ditinjau dari kesesuaian soal dengan Kompetensi Dasar sebagian besar sudah sesuai, namun masih ada Kompetensi Dasar yang belum diukur dalam Penilaian Akhir Semester (PAS), yaitu KD 3.3, KD 3.6 dan KD 3.8.

Aspek materi soal pada penelitian ini tergolong sangat baik, batasan pertanyaan dan jawaban yang diharapkan, dan isi materi yang ditanyakan hampir secara keseluruhan sesuai, namun terdapat satu soal batasan pertanyaan dan jawaban yang diharapkan belum sesuai.

Aspek bahasa pada penelitian ini tergolong cukup baik. Sebagian besar guru dari setiap sekolah masih belum memperhatikan dari segi bahasa soal khususnya butir soal yang dibuat menggunakan bahasa Indonesia yang baku.

Sebagian besar kualitas soal penilaian akhir semester buatan guru yang paling rendah terdapat pada aspek konstruksi. Perlu adanya upaya perbaikan pada pembuatan petunjuk soal yang jelas tentang cara mengerjakan soal dan soal menggunakan kata tanya atau perintah yang menuntut jawaban terurai.

Distribusi jenjang ranah kognitif taksonomi Bloom yang terukur adalah $\mathrm{C} 1$ sebesar 24\%, C2 sebesar 12\%, C3 sebesar 60\%, C4 sebesar 4\%. Belum ditemukan soal-soal berpikir tingkat tinggi.

Secara empirical review ditinjau dari tingkat kesukaran soal, soal kategori sukar terdapat $12 \%$ soal, kategori sedang terdapat $68 \%$ soal, dan kategori mudah terdapat $20 \%$. Daya beda soal secara keseluruhan, soal yang diterima baik 
terdapat $64 \%$, terdapat $28 \%$ soal yang direvisi, dan terdapat $8 \%$ soal yang dibuang. Tingkat kesukaran dan daya beda soal diperoleh rata-rata soal yang baik sebanyak $68 \%$ soal yang memenuhi kriteria analisis berdasarkan empirical review dari setiap sekolah. Reliabilitas soal penilaian akhir semester tiap sekolah tergolong tinggi dengan koefisien rata-rata Alpha Cronbach sebesar 0,85.

Berdasarkan hasil penelitian maka peneliti mengajukan beberapa saran, yaitu:

(a) Guru-guru SMA khususnya guru SMA di Kabupaten Barito Timur perlu memperhatikan hal dalam upaya mencapai karakteristik soal yang baik, yaitu pembuatan soal. Mengikuti kegiatan seperti pelatihan atau workshop bisa membantu para guru-guru melakukan analisis dan pembuatan soal yang baik terhadap soal-soal yang hendak digunakan dalam tes.

(b) Kepala Sekolah perlu memperhatikan tingkat keterampilan guru dalam membuat soal tes agar sekolah memiliki keunggulan dalam penyusunan tes. (c) Dinas Pendidikan Nasional Kabupaten Barito Timur diharapkan dapat mensosialisasikan hasil penelitian ini dalam upaya perbaikan, peningkatan, dan penyempurnaan kualitas pembelajaran dan evaluasi di Barito Timur. (d) Terbuka kemungkinan diadakan penelitian sejenis dan berkelanjutan dengan objek yang lebih luas agar hasil yang diperoleh dapat menjadi gambaran secara umum karakteristik soal yang baik.

\section{Daftar Pustaka}

Arikunto, Suharsimi. 2013. Dasar-Dasar Evaluasi Pendidikan edisi 2. Jakarta: Bumi aksara. 
Irfan Syani (282-299)

Purwanto, Ngalim. 2008. Prinsip-prinsip dan Teknik Evaluasi Pengajaran. Bandung: Rosda Karya.

Putra, Sitiatava R. 2013. Desain Evaluasi Belajar Berbasis Kinerja. Yogyakarta: Diva Press.

Widoyoko, Eko P. 2016. Hasil Pembelajaran Di Sekolah edisi revisi. Yogyakarta: Pustaka Pelajar. 